\title{
Aging Population and Its Impacts on Economy of Vietnam
}

\author{
Nguyen Tan Danh
}

FPT University, Vietnam

Email: nguyentandanh0774@gmail.com

Article History: Received: 11 January 2021; Accepted: 27 February 2021; Published online: 5 April 2021

\begin{abstract}
The proportion of the elderly in Vietnam is happening with rapidly growing numbers. This is an inevitable trend in Vietnamese society, and also a problem - a challenge for the government. The main goal of our country in particular is to point out and face the immediate situation (high aging rate of the population), and at the same time find a strategy that is suitable for the development of the country as well as consistent with the common interests of the current elderly group; making predictions to take the right steps to minimize the risks and risks from its negative sides. This article discusses the general situation of population aging in recent years in Vietnam; give specific numbers and statistics on this issue. From there, this article will highlight the opportunities and challenges that this country is facing - especially the impact on the country's economy and give a number of recommendations related to the improvementin order to build a satisfactory welfare and welfare system for the elderly in the current aging population in Vietnam. The article uses the method of surveying a number of interviewers to find suitable solutions, and the results show that the problem of the elderly, even though not alarmed since the elderly in Vietnam are still taken care by children and their families rather well. However, there is quite a big concern we need to pay more attention, that is, the economic burden will be an issue for society in the future, especially in the medical field.
\end{abstract}

Keywords: population aging, the elderly, welfare

\section{INTRODUCTION}

Population or in other words human is the foundation in the development of society and the country [1]. However, after a long time being proud of being a populous country, at present, Vietnam is facing many great challenges in terms of size, structure or quality of its population. This has greatly affected the current national development [2]. Some typical problems that begin to arise are the emergence of phenomena that can be influenced by many different reasons, such as influenced by the mix of cultures, or individual problems within each family, but the young population structure is gradually changing, "young population structure" to "golden population structure" and "old population structure" [3] [4].

The biggest possible future challenge is whether Vietnam is under pressure to see a shrinking young workforce, etc. The rapid growth of the elderly is the cause of concerns about decision-making, our current state reciprocal methods such as transforming the pressure on population growth. Old age becomes the driving force in creating economic potential (attracting foreign investment into Vietnam, encouraging domestic enterprises to have a strategy in the production and trading of products for the elderly or have social security policies such as retirement, health insurance, social insurance etc.) [5].

The following contents will be analyzed in depth with some recommendations based on the implementation of the survey data, charts, statistics in recent years.

\section{THE CONTENT OF THE RESEARCH PAPER}

\subsection{Literature Review}

For entrepreneurs, understanding the demographic characteristics of the elderly will help them to have appropriate production and business strategies to meet the needs of this group of people to consume goods and services "[6]. Over the last three decades, the fertility rate in Vietnam has decreased from about $2.4 \%$ to $1.3 \%$ in 2005 and $1.2 \%$ in 2008 . This indicates that the proportion of children has decreased, while the proportion of the population in working age and the non-working population increased [7].

The current fertility rate has decreased quite a lot over the years on a global scale in general and in Vietnam in particular. It is this process that is responsible for the dramatic increase in the number of older people in many countries. And Vietnam is not an exception, this means that Vietnam is facing the risk of aging population in the future. 
Many speculations suggest that this process affects growth and causes problems for the economy. However, population aging, which has a negative impact on growth, is not certain. Therefore the relationship between aging and growth cannot really make a precise argument [8].

Recent studies in several countries in Europe have found a statistical correlation between the aging population and the decline in productivity. Specifically, they focused on how a population with more older people in general is also a population with more older people among those still of working age affecting productivity. Apparently, older workers are slow to adapt to changing circumstances, technologies and business models, and therefore less productive [9].

However, in 2017, economists Daron Acemoglu and Pascual Restrepo studied the per capita GDP growth rate between 1995 and 2015 in many countries and compared the change in the proportion of older people with the number of people of working age during the same period. Contrary to the popular assumption above, this study basically found no such relationship at all.

An often-cited example of aging is Japan, which has actually seen a sharp drop in fertility, a high proportion of the elderly, and a marked slump in the economy. But Acemoglu and Restrepo have compared Japan's aging rate to GDP per capita growth with many countries and show that the relationship is not clear [10].

\subsection{Current situation of population aging in Vietnam today}

Vietnam in particular is a country with a diverse population structure. Over the past 30 years, according to the Population Census $(1979,1989,1999,2009)$, the proportion of the elderly in Vietnam has increased by an average of $0.06 \%$ each year. But notably here, from 1.4.2009 to 1.4 .2010 , the proportion of the elderly aged 60 and over has increased significantly: $8.67 \%$ to $9.4 \%$, the elderly group from 65 increases $6.4 \%$ to $6.8 \%$. These parameters alarmed the current situation of Vietnam. Within 1 year, the number of elderly people has increased 10 times compared to previous years.

In addition, the proportion of the elderly without economic accumulation is very high, $70 \%$ of the elderly population living in Vietnam continue to work even at retirement age. In addition, the health status of people over the age of 60 in Vietnam is on the alert, most of them suffer from some diseases such as diseases of the joints, respiratory or cardiovascular diseases, etc. This is very large and leads to high costs of medical care, creating an overwhelming pressure on hospitals that have not yet fully solved these problems [6].

\subsection{The reason for the increase in the proportion of the elderly population since 2011}

Population aging is an inevitable process. However, if Sweden takes 85 years or Japan about 26 years when transitioning to aging, Vietnam only has 15-20 years.

The aging population reflects a medical industry that has made great progress, making the health of Vietnamese people in particular gradually improved, in which economic development is also one of the factors. causes a quantitative change to result in a qualitative change. When people have a solid economic base, they gradually begin to focus more on their spiritual life, which affects their life expectancy more and more.

\subsection{Research method, subject \& scope}

This article is completed based on comparative studies with survey data at some places in Ho Chi Minh city. The respondents of the survey are people with different jobs. The method of conducting research is to conduct online surveys and directly interview these respondents during about 2 weeks of December, 2020.

The reason for choosing the direct interview method is because both of these methods will bring visual results to help readers have a more comprehensive view of the research results.

\subsection{Research results}

Based on the current personal income survey at the age of 50-65 years old, this age group is mostly workers who are currently working at companies, markets or shops. Most of them are working, therefore they have income but rather low income and the income is just enough to spend for their personal expenses. About $62.5 \%$ of them have an income of between 300-400 USD per month and the remaining are living on subsistence income (Figure 1). 


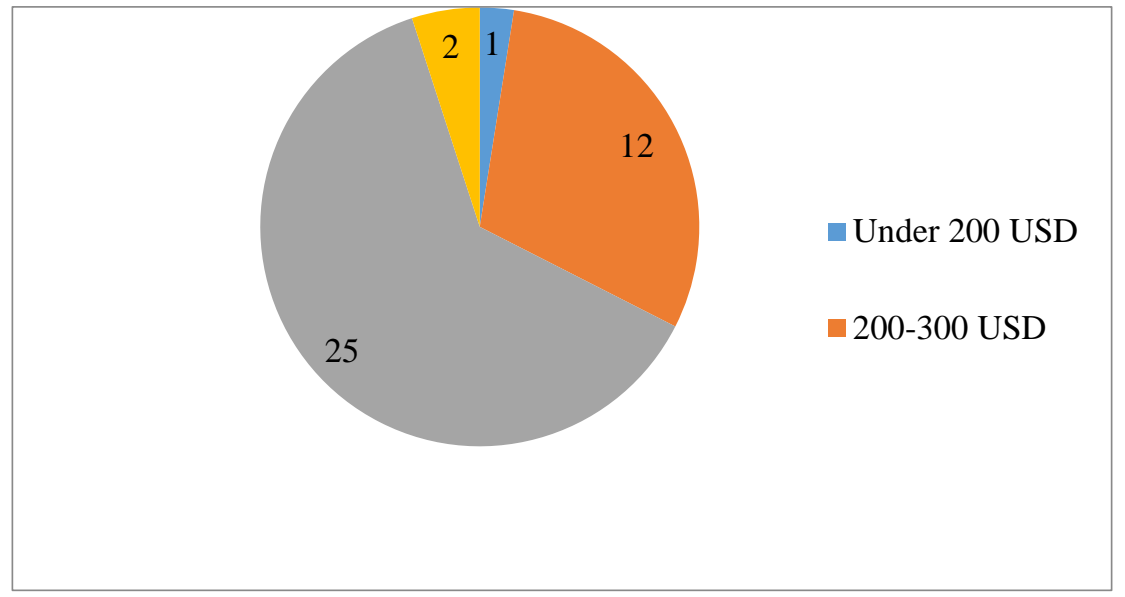

Figure 1. Current income of the respondents

That means whether $62.5 \%$ of them or $37.5 \%$ of the respondents living on subsistence can only take care of themselves. People who are at retirement age in the family must take care of their own personal activities, depending on pensions or on the support of the members in the "golden" age.

In fact, not only worrying about health care, the elderly are also facing many difficulties in their life. Up to $70 \%$ of the elderly live in rural areas and have no material accumulation, mainly rely on social care, their descendants or self-employed without accumulation. Elderly people often consider their descendants as a support when they get old, however, the trend of traditional family size in Vietnam is gradually shifting to the nuclear family model, making many old people more lonely have many difficulties when living alone. Not to mention a part of young people today consider the elderly as a burden [4]. Many views suggest that "aging" of the population will be a burden for socio-economic development. However, sociologists and population experts say that this is a wrong view that we must change. Population aging must be considered as a great social achievement of mankind and nations. Currently, there is a healthy part of the elderly, which is a valuable human resource, but we do not know how to utilize their knowledge and experience. If properly supported, the elderly can continue to make great contributions to their families, communities and the country [7]. All the elderly need access to basic social services and medical care; they need to live healthy and contribute their valuable skills and experiences to society. It is necessary to convert the perception that "the elderly are burdensome" to "the elderly are assets" to have appropriate policies and programs.

Population aging is not a burden but a great achievement for mankind. However, with the rate of aging too fast and the transition from "golden population" to too short an aging population, our country will face many challenges in health care and well-being. society for the elderly, if there are no timely solutions, on average, each elderly Vietnam suffers 7.3 years of illness in their lives, so the need for health care for the elderly is a problem great deal.

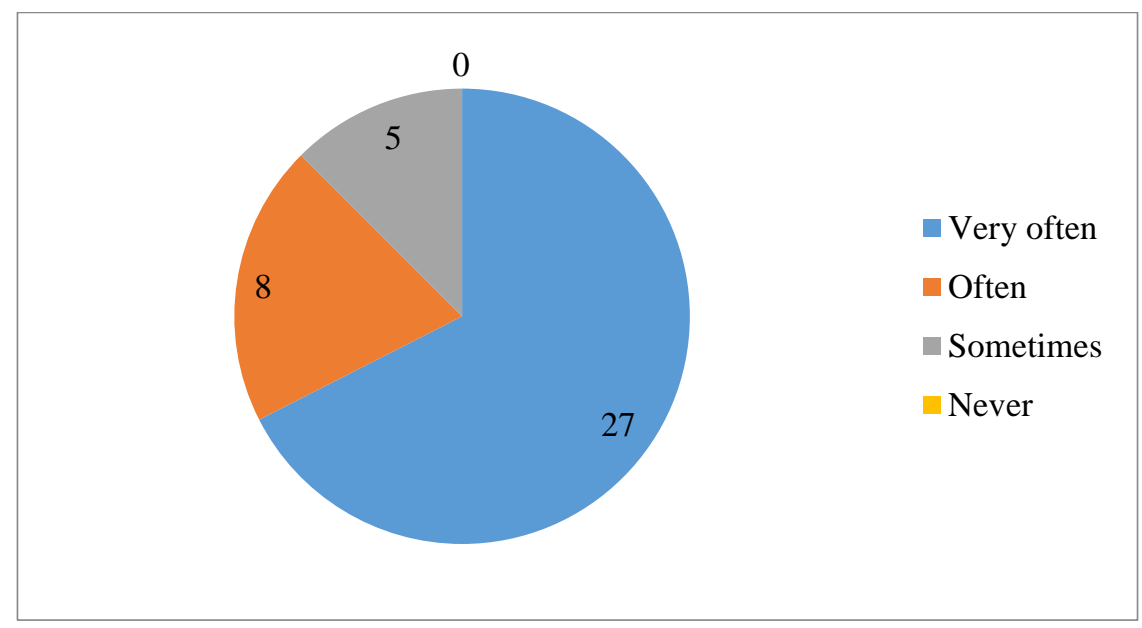

Figure 2. The frequent use of medical services 
When being asked about the medical fee to pay for the old people, some respondents mentioned that medical care for a child needs one dollar, care for the elderly needs eight dollars. For the elderly, care requires increasingly higher costs when switching from the structure of infectious diseases to the structure of metabolic diseases, noncommunicable diseases such as diabetes, fat metabolism disorder, high blood pressure, accidents, injuries, etc. require higher costs of long-term medical care, and an increased risk of disability. According to statistics of the Ministry of Health, $95 \%$ of the elderly have diseases, mainly chronic diseases such as heart disease, blood pressure, diabetes, etc. In fact, the national survey on the elderly shows, only $4.8 \%$ of the elderly saying that their health status is good and very good, the remaining $65.4 \%$ of the elderly say they have normal health and $29.8 \%$ are weak and very weak. 27 of the respondents $(67.5 \%)$ said that the old people in their families usually go to hospital to see the doctor, that means that the elderly goes to hospital at least one time per year and many a time they get medication from a drug store for some normal symptoms of disease (Figure 2).

\subsection{Some suggestions for inserting references}

The primary concern in developing countries like Vietnam today is securing the income of the elderly. This is a frequently mentioned issue and also a difficult challenge beyond medical services.

To solve the living problems of the elderly, the pension system is considered as one of the important measures to ensure the economic independence of the retirement age [6]. Pensions, especially social pensions, are very important for the elderly because they not only contribute to improving the well-being of the retired population, but are also meaningful to the entire population. elderly family. Typically, during the economic crisis caused by the Covid -19 epidemic, pensions were almost the main source of income for the whole household [3]. This is the main amount of support for young people and their families to overcome the period of unemployment, or unpaid leave.

Next is access to quality medical care. In order for the elderly population to be aware of their right to physical and mental life, it is necessary to provide them with access to information and health care services that are relevant to their own living needs. Policies to promote healthy lifestyles, technology support, and difficulties in information acquisition and advocacy are needed [7]. Housing and transportation are essential to maintaining an independent life, communicating with society and promoting communication with the outside world while allowing the elderly to actively contribute to society. .

The State should have stricter sanctions against acts of violence, discrimination, abuse or violence against the elderly. There is also a need to further strengthen flexible and appropriate employment opportunities, and opportunities for long-term continuing education and training to promote the integration of the elderly in the current generation's labor market.

Changing perceptions and perceptions and attitudes of the society on aging and the elderly, seeing the elderly not from the perspective of social welfare recipients but as active contributors in the commune festival.

In order to raise awareness and responsibility for health care for the elderly in the context of population aging, thereby calling on the political system and social organizations to join hands to participate in care work. health of the elderly, especially in the community [9]. The Vietnam Association for Community Health Education has cooperated with the Vietnam Elderly Association to organize a Forum on Healthcare for the elderly in the community.

Along with that, Vietnamese elderly live mainly in the countryside, living with their descendants; material life still faces many difficulties. Elderly people face the burden of "double disease" and often suffer from chronic diseases [10]. On average, each elderly person has 3 diseases, facing the risk of disability due to the aging process, and large treatment costs.

However, the health care system in general and primary health care in particular have not adapted to rapidly aging population. The building of a friendly environment for the elderly and the implementation of various types of longterm health care in the community have not been given adequate attention [4].

Affirming that the care and promotion of the role of the elderly in the current rapidly aging population is extremely important and urgent, in the coming time, the elderly generations, depending on Each health condition, field and professional ability will continue to contribute to economic, educational and social activities to mentor the young generation as well as contribute to building the stronger country [8].

\section{CONCLUSION}


This article describes the changing trend of the Vietnamese population as well as shows that Vietnam will enter the period of aging at a rapid rate while the preparation time is very short. In that trend, the article mentions the current situation of aging population, especially the period 2009-2010 to point out the challenges facing the country. Since then, this article gives a number of recommendations on policies to ensure adaptation to aging population and improve health care for the elderly and social security system, to facilitate for the elderly to continue participating in economic activities will help improve living standards, contribute to promoting production of goods and services. In addition, delaying reform on a comprehensive or only partial reform will lead us to face "reforms that never end" with the challenges outlined above.

\section{ACKNOWLEDGMENTS}

I would like to appriciate the assistance of the respondents who helped me to fill the survey and gave face-to-face interviews for the study to be completed.

\section{REFERENCES}

[1] Giang, L. T., Pham, T. H. T., \& Phi, P. M. 2019. Productive activities of the older people in Vietnam. Social Science \& Medicine, 229, 32-40.

[2] Friedman, J., Goodkind, D., Cuong, B. T., \& Anh, T. S. (2001). Work and retirement among the elderly in Vietnam. Research on Aging, 23(2), 209-232.

[3] Yoshino, N., Kim, C. J., \& Sirivunnabood, P. 2019. Aging Population and its Impacts on Fiscal Sustainability. Aging SocietieS.

[4] Hoi, H. T. 2020. Factors Affecting Employee Retention in Japanese Enterprises in Vietnam. Test engineering and management journal, 83, 5645-5651.

[5] Čiutienè, R., \& Railaitè, R. 2015. A development of human capital in the context of an aging population. Procedia-Social and Behavioral Sciences, 213, 753-757.

[6] Poterba, J. M. 2014. Retirement security in an aging population. American Economic Review, 104(5), 130.

[7] Lin, M. H., Chou, M. Y., Liang, C. K., Peng, L. N., \& Chen, L. K. 2010. Population aging and its impacts: strategies of the health-care system in Taipei. Ageing research reviews, 9, S23-S27.

[8] Hoi, H. T. 2020. Advertising Vietnam's Tourism Products in the Technology Age. In Proceedings of the 2020 International Conference on Management of e-Commerce and e-Government, 11-15.

[9] Nishiyama, S. 2015. Fiscal policy effects in a heterogeneous-agent OLG economy with an aging population. Journal of Economic Dynamics and Control, 61, 114-132.

[10]Bloom, D. E., Canning, D., \& Fink, G. 2010. Implications of population ageing for economic growth. Oxford review of economic policy, 26(4), 583-612. 